\title{
Biomechanical considerations in the pathogenesis of osteoarthritis of the knee
}

\author{
Andras Heijink • Andreas H. Gomoll • \\ Henning Madry • Matej Drobnič • Giuseppe Filardo • \\ João Espregueira-Mendes · C. Niek Van Dijk
}

Received: 8 August 2011/Accepted: 22 November 2011/Published online: 16 December 2011

(C) The Author(s) 2011. This article is published with open access at Springerlink.com

\begin{abstract}
Osteoarthritis is the most common joint disease and a major cause of disability. The knee is the large joint most affected. While chronological age is the single most important risk factor of osteoarthritis, the pathogenesis of knee osteoarthritis in the young patient is predominantly related to an unfavorable biomechanical environment at the joint. This results in mechanical demand that exceeds the ability of a joint to repair and maintain itself, predisposing the articular cartilage to premature degeneration. This review examines the available basic science, preclinical and clinical evidence regarding several such unfavorable
\end{abstract}

A. Heijink $(\bowtie) \cdot$ C. N. Van Dijk

Department of Orthopaedic Surgery, Academic Medical Center (AMC), Meibergdreef 9, 1105 AZ Amsterdam, The Netherlands e-mail: a.heijink@amc.nl

\author{
A. H. Gomoll \\ Department of Orthopaedic Surgery, Brigham and Women's \\ Hospital, Harvard Medical School, Boston, MA, USA
}

H. Madry

Experimental Orthopaedics and Osteoarthritis Research and Department of Orthopaedic Surgery, Saarland University

Medical Center, Homburg/Saar, Germany

H. Madry

Saarland University, Homburg/Saar, Germany

\section{Drobnič}

Department of Orthopaedic Surgery, University Medical Center Ljubljana, Ljubljana, Slovenia

G. Filardo

III Clinic, Biomechanics Laboratory, Rizzoli Orthopedic Institute, Bologna, Italy

J. Espregueira-Mendes

Clínica Saúde Atlântica, Minho and Porto Universities,

Porto, Portugal biomechanical conditions about the knee: malalignment, loss of meniscal tissue, cartilage defects and joint instability or laxity.

Level of evidence IV.

Keywords Cartilage - Malalignment - Meniscus · Osteochondral defects · Joint instability · Pathology · Etiology

\section{Introduction}

Osteoarthritis is the most common joint disease. It is characterized by joint pain and dysfunction and, in advanced stages, joint contractures, muscle atrophy and limb deformity. The knee is the large joint most commonly affected.

The primary changes with osteoarthritis occur in the articular cartilage, followed by associated changes in the subchondral bone [25, 88]. Recently, more focus has been placed on the subchondral bone as the primary cause of symptomatic disease [60, 61, 93, 141]. Understanding of changes early in the development of osteoarthritis (early osteoarthritis) is important, since these changes could still be reversible, and therefore, preventive treatment could be initiated to halt or reverse further progression of the disease. This is especially true in the young patient.

The etiology of osteoarthritis is multifactorial and to date not fully understood. Age is the major independent risk factor of osteoarthritis; however, aging and osteoarthritis are inter-related, not inter-dependent [88]. Where cartilage senescence is to some extent part of normal aging and the relationship between aging and the development of osteoarthritis is incompletely understood, it is becoming apparent that aging changes in the musculoskeletal system contribute to the development of osteoarthritis by working 
in conjunction with other factors, both intrinsic (e.g., alignment, overloading) and extrinsic (e.g., genetics) to the joint [88]. In the young patient, the pathogenesis of knee osteoarthritis is predominantly related to an unfavorable biomechanical environment at the joint, which results in mechanical demand that exceeds the ability of a joint to repair and maintain itself, predisposing the articular cartilage to premature degeneration [26]. The pathophysiology of the process by which joint degeneration leads to the clinical syndrome of osteoarthritis remains poorly understood.

In this review, the pathophysiological mechanisms by which biomechanical conditions about the knee can lead to the development of osteoarthritis are discussed (Table 2), and the relation of distinct clinical conditions about the knee (malalignment, loss of meniscal tissue, cartilage defects and joint instability) and the development and progression of clinical and/or radiographic osteoarthritis are evaluated. In this review, first, normal cartilage structure and function, and histopathological changes with normal aging are discussed. Then, cartilage loading and the pathophysiological impact of overloading are reviewed. The impact of trauma on cartilage is discussed separately. Last, the relation and pathophysiological changes related to distinct unfavorable biomechanical conditions about the knee (malalignment, loss of meniscal tissue, cartilage defects and joint instability) and clinical and/or radiographic osteoarthritis are evaluated.

\section{Cartilage structure, function and homeostasis}

\section{Normal structure and function}

Articular cartilage consists primarily of extracellular matrix with a sparse population of cells, lacking blood vessels, lymphatic vessels and nerves [25, 28]. It has a low level of metabolic activity, and there is little or no cell division or cell death in normal adult articular cartilage, although articular chondrocytes are in fact capable of cell division [4, 25, 87, 88, 123]. The chondrocytes, making up only about $1 \%$ of volume of adult human articular cartilage [25], is the one cell type present in articular cartilage and, therefore, is responsible for both the synthesis and the breakdown of the cartilaginous matrix [25, 60, 87]. The mechanisms that control the balance between synthesis and degradation remain poorly understood, but cytokines with anabolic and catabolic effects appear to have important roles [25, 60].

For articular cartilage to exert its normal function within the joint, it needs to be elastic and have high tensile strength. The unique mechanical properties of articular cartilage depend on the extracellular matrix [25]. This extracellular matrix consists of two components, tissue fluid and the framework of structural macromolecules consisting of type II collagen fibers, proteoglycans and non-collagenous proteins and glycoproteins, all produced in the appropriate amounts and assembled and organized into a highly ordered molecular framework by the chondrocytes [25, 28]. The collagen matrix gives cartilage its form and tensile strength [25]. Proteoglycans and noncollagenous proteins bind to the collagenous network, help stabilize the matrix macromolecular framework and help chondrocytes bind to the macromolecules of the network [25].

Osteoarthritis is disruption of homeostasis

Osteoarthritis results from failure of chondrocytes to maintain the homeostasis between synthesis and degradation of these extracellular matrix components $[4,25,26$, $60,88]$. This disruption of homeostasis results in increased water content and decreased proteoglycan content of the extracellular matrix; and weakening of the collagen network due to decreased synthesis of type II collagen and increased breakdown of pre-existing collagen [25]. Furthermore, there is increased apoptosis of chondrocytes. At first, compensatory mechanisms, such as increased synthesis of matrix molecules and proliferation of chondrocytes in the deeper layers of the cartilage, are able to maintain the integrity of the articular cartilage, but eventually loss of chondrocytes and changes in extracellular matrix predominate and osteoarthritic changes develop $[25,28]$.

Aging and cartilage

Since there is little or no cell division or cell death in adult articular cartilage, chondrocytes are thought to be longlived cells and, therefore, can accumulate age-related changes over time $[4,25,87,88]$. As a consequence, aging profoundly alters chondrocyte function and matrix structure and functioning (Table 1).

There appears to be an age-related reduction in the number of chondrocytes in articular cartilage, but the extent of cell loss is debated [87]. Little data are available about the occurrence of apoptosis in chondrocytes, with the exemption of the finding of increased apoptosis in rat cartilage with aging [2]. Telomere shortening, a classic feature of cell senescence, has been observed in chondrocytes [87]. However, since cell turnover is so low, it seems unlikely that these shortened telomeres represent replicative senescence, which generally require more than 30-40 cell replication cycles $[67,88]$. Telomere shortening can also result from stress-induced senescence, which seems the more likely mechanism in cartilage, with chronic 
inflammation and oxidative stress being offending factors [44, 88] (Table 2).

There is increasing evidence that cell senescence can result in phenotypical alteration of cells, called the senescent secretory phenotype [32, 33]. This phenotype is characterized by increased production of cytokines and growth factors. Accumulation of cells expressing this senescent secretory phenotype may contribute to tissue aging, by stimulating matrix degradation en reducing matrix synthesis and repair, and possibly even directly link aging to joint degeneration [88].

Chondrocytes become less responsive to growth factors with aging, thereby further reducing matrix synthesis and repair. A decline in response to insulin-like growth factor-I (IGF-I), possibly due to altered signaling, may, due to its important autocrine effect on survival [86], also be implicated in age-related cell death [88].

Age-related changes in size, structure and sulfation of aggrecan, the molecules in cartilage matrix that hold water, have been reported, changing the biophysical properties of cartilage matrix and therefore reducing its resiliency and tensile strength $[15,27,51,152]$.

Furthermore, articular cartilage has a relatively low turn-over rate and is therefore susceptible to accumulation of advanced glycation end-products, resulting from spontaneous nonenzymatic glycation of proteins [146, 147]. Increased collagen cross-linking due to modification of collagen by AGE formation renders the cartilage more brittle with increased fatigue failure [88]. A role in the development of osteoarthritis has been suggested [47, 146].

There is increasing evidence that oxidative stress due to chronic production of endogenous reactive oxygen species (ROS or "free radicals") plays an important role in aging and in the link between aging and osteoarthritis [87-89]. Increased levels of ROS can damage DNA, including mitochondrial DNA, thereby affecting cell viability and contributing to the disruption of extracellular matrix homeostasis [45, 65]. Increased levels of ROS may also contribute to the senescent secretory phenotype [157] and the reduced sensitivity of chondrocytes to IGF-I [156].

Table 1 Aging changes in joint tissues and the contribution of aging to the development of osteoarthritis

\begin{tabular}{ll}
\hline Aging change & Contribution to OA \\
\hline Accumulation of cells exhibiting the senescent secretory phenotype & $\begin{array}{c}\text { Increased cytokine and MMP production stimulates matrix } \\
\text { degradation } \\
\text { Increased susceptibility to cell death and reduced matrix synthesis } \\
\text { Reduced matrix synthesis and repair }\end{array}$ \\
$\begin{array}{l}\text { Oxidative stress/damage } \\
\text { recreased levels of growth factors and decreased growth factor }\end{array}$ & $\begin{array}{l}\text { Brittle tissue with increased fatigue failure } \\
\text { Contribution to OA } \\
\text { Increased AGE formation }\end{array}$ \\
$\begin{array}{l}\text { Aging change } \\
\text { Accumulation of cells exhibiting the senescent secretory phenotype } \\
\text { degradation }\end{array}$ \\
\hline
\end{tabular}

Adapted with permission from: Shane and Loeser [123]

Table 2 Unfavorable biomechanical conditions about the knee joint and the mechanisms by which they result in relative overloading of the articular cartilage

\begin{tabular}{|c|c|}
\hline $\begin{array}{l}\text { Unfavorable biomechanical } \\
\text { condition }\end{array}$ & Mechanism of relative cartilage overloading \\
\hline Malalignment & $\begin{array}{l}\text { Abnormal load distribution due to shifting of the center of pressure of the tibiofemoral force, resulting in locally } \\
\text { increased stresses on the articular cartilage }\end{array}$ \\
\hline Loss of meniscal tissue & $\begin{array}{l}\text { Alteration in load transmission, resulting in increased peak local stresses on the articular cartilage } \\
\text { (Partial) loss of secondary constraint to anteroposterior translation in unstable (i.e. anterior cruciate ligament- } \\
\text { deficient) knees }\end{array}$ \\
\hline Cartilage lesions & $\begin{array}{l}\text { Increased stresses on the lesion rim of diameters greater than } 10 \mathrm{~mm} \\
\text { Increased exposure of subchondral bone leading to endplate stiffening and microcracks }\end{array}$ \\
\hline $\begin{array}{l}\text { Joint instability or ligament } \\
\text { laxity }\end{array}$ & $\begin{array}{l}\text { Abnormal load distribution due to shifting of the center of pressure of the tibiofemoral force, resulting in locally } \\
\text { increased stresses on the articular cartilage } \\
\text { Increased translation between articular surfaces, resulting in increased shear stresses on the articular cartilage }\end{array}$ \\
\hline Trauma & $\begin{array}{l}\text { Cartilage damage due to traumatic impact per se } \\
\text { Increased metabolic and oxidative stress of chondrocytes, resulting in accelerated chondrocyte senescence }\end{array}$ \\
\hline
\end{tabular}


As stated earlier, the etiology of osteoarthritis is multifactorial and aging contributes, but does not directly cause osteoarthritis. The various factors that contribute to the development of osteoarthritis by working in conjunction with aging changes are best understood in the way they accelerate the above-discussed so-called 'normal' aging changes: through mechanical damage of the cartilage, through intrinsic modifications in components of the extracellular matrix or of the chondrocytes, or through alterations in cell-matrix interactions. Association of aging and osteoarthritis involves all these elements [77].

\section{Cartilage loading and overloading}

\section{Cartilage loading and overloading}

Joint loading can induce a wide range of metabolic responses in articular cartilage. The mechanisms by which chondrocyte-mediated production of extracellular matrix components responds to mechanical stimuli are only beginning to be understood $[25,26]$. There are multiple regulatory pathways by which chondrocytes sense and react to mechanical stimuli, including upstream signaling pathways and mechanisms that may lead to direct changes at the level of transcription, translation, posttranslational modifications, and cell-mediated extracellular assembly and degradation of matrix [25, 64, 139]. Also, there are multiple pathways by which physical stimuli can alter not only the rate of matrix production, but also the quality and functionality of newly synthesized proteoglycans, collagens, and other molecules [25].

Normal synovial joints can withstand repetitive loading during normal activities for a lifetime without developing osteoarthritis [26, 140]. However, mechanical demand that exceeds the tolerance, that is, the ability to repair and maintain itself, of the articular cartilage, plays an important role in the development and progression of joint degeneration in all forms [25, 26]. Excessive mechanical surface contact stress can directly damage articular cartilage and subchondral bone and adversely alter chondrocyte function [26]. In experimental setting, it has been shown that cartilage cannot survive more than $25 \mathrm{MPa}$ of impulsive contact stress. Since physiological peak contact stresses are several fold less, there appears to be a built-in 'safety' factor [26]. The in vivo tolerance of human cartilage to surface contact stress is not known, but an association between high mechanical demand and degenerative changes of the hip joint has been observed. In addition, joint apposition and engagement are important determinants of cartilage damage following an impact event. Also, substantial acute micro-damage (e.g., micro-fractures, cartilage fissures, chondrocytes death, proteoglycan release) can result from impact levels far below the level needed to produce macroscopic fracture. This micro-damage may progress to detectable compromise of the mechanical integrity of the articular cartilage. Furthermore, loading rate [53] and shear stress [11, 12] are important variables.

Many clinical conditions about the knee can result in excessive mechanical demand or overloading of the either intact or already damaged articular cartilage: diffusely, due to obesity and high-impact sports; or, more focally, due to uneven load distribution with joint malalignment, after loss of meniscal tissue or at the edges of cartilage defects and post-traumatic joint incongruities.

Post-traumatic osteoarthritis

Clinical experience shows that the development and progression of post-traumatic osteoarthritis is not necessary due to rapid wear of an irregular articular surface alone [97]. The relationship between residual osseous depression of the joint surface and development of osteoarthritis is very inconsistent. Even when joint congruity, alignment and stability are adequately restored, the joint may degenerate [96]. On the other hand, apparently normal articular surfaces often degenerate following injuries as well [96].

The mechanisms responsible for the development of osteoarthritis following acute injury remain incompletely understood. Experimental work has shown that both pulses of acute energy and chronic mechanical overload damage and cause or accelerate degeneration of this articular cartilage [24]. The theoretical goal of anatomically reconstructing the joint is to decrease joint incongruity, malalignment and instability, thereby avoiding, or at least decreasing, focally elevated contact stresses, which are thought to be in large part responsible for the development of post-traumatic osteoarthritis. However, the in vivo tolerance of articular cartilage to both acutely or chronically increased stress and the potential to repair and remodel itself remain largely unknown $[26,96]$. Cartilage metabolism appears to be particularly sensitive to loading rate [24], the effect of which to date has only sparsely been taken into consideration in the experimental work on posttraumatic osteoarthritis.

From experimental data, it is observed that certain patterns of increased mechanical stress, in particular high levels of shear stress, increase production of free oxygen radicals and decrease synthesis of proteoglycans; and that this increased oxidative stress on chondrocytes accelerates chondrocyte senescence [97]. It is thus concluded that chondrocyte senescence contributes to the risk of posttraumatic articular cartilage degeneration by decreasing the ability of the cells to maintain and repair the tissue [97]. This oxidative stress-related damage is in addition to 
damage due to chondrocyte senescence resulting from increased metabolic stress resulting from the trauma impact and following the repair response that was already taken place [97]. Experimental studies suggest that, despite its adverse effects on cartilage, a period of non-weight bearing may also have its advantages in that it may be protective against some types of chemically induced damage to chondrocytes [19, 22]. In addition, there is increasing evidence that biological interventions can decrease mechanical stress-induced chondrocyte damage [26, 42, 43, 81].

An interesting and clinically important question is if, and to what extent this mechanism of oxidative stressrelated chondrocyte senescence and resulting cartilage degeneration also occurs with altered stress patterns in the joint as seen with malalignment, loss of meniscal tissue, cartilage defects and joint instability. Further studies are needed to shed light on this issue.

\section{Malalignment, loss of meniscal tissue, cartilage defects and joint instability}

\section{Malalignment}

In the normally aligned knee, the center of pressure of the tibiofemoral force passes slightly through the medial side of the knee during stance (average of 4-8 mm medial to the knee joint center) [114], reaching an average peak force of about 3 times body weight (BW) during walking and of about 6 times BW during stair climbing [126, 134]. During flexion, this center of pressure lies even more medial. Varus or valgus malalignment of the lower extremity results in an abnormal load distribution across the medial and lateral tibiofemoral compartment [135]. For example, a 4-6\% increase in varus alignment increases loading in the medial compartment by up to $20 \%$ [135]. Since axial malalignment increases the stress on the articular cartilage and the subchondral bone, it has been suggested to play an important role early in the development of early osteoarthritis [62]. Indeed, increased knee joint loads are present in patients with knee osteoarthritis [13], and the interaction between axial alignment and dynamic knee joint loadingthe loading of the knee joint during gait [8, 18]-is especially pronounced in patients with a high body mass [103]. However, studies examining the relationship between malalignment and early knee osteoarthritis have produced conflicting results.

A possible relationship between the incidence of early osteoarthritic changes and axial malalignment is only supported by limited evidence so far. The Multicenter Osteoarthritis Study (MOST) radiographically identified cartilage loss in early osteoarthritis in the same subregions within the knee as subchondral bone attrition [106]. Subchondral bone attrition, characterized by a flattening or depression of the subchondral bone, therefore may indicate an increased load transmitted through the articular cartilage. In patients with varus malalignment, subchondral bone attrition was found in the medial compartment; and in patients with valgus malalignment in the lateral compartment. Brouwer et al. [21] reported an association between valgus and varus alignment and the development of radiographic osteoarthritis of the knee. This relationship was more pronounced in obese patients, compared to the non-obese. Further study of the relation between malalignment, obesity and the development of early osteoarthritic changes is needed.

In contrast, the correlation between the progression of early osteoarthritic changes and axial malalignment has been well established. Both conventional radiological [21, 34, 102, 124] and MRI [38, 55] studies found that axial malalignment is a potent risk factor for progression of early osteoarthritic changes in patients with axial malalignment [133]. Importantly, the articular cartilage loss [106] and subchondral bone changes [107] may in turn increase malalignment. Cicuttini et al. [38] reported that the degree of varus knee angle was associated with a reduction in the volume of both femoral and tibial articular cartilage in the medial tibiofemoral compartment of the knee over a 1.9year follow-up period. Similar results were seen in the lateral tibiofemoral compartment.

The rationale for high tibial osteotomy (HTO) is slowing or preventing early osteoarthritic changes by restoring a more favorable biomechanical situation, thereby reducing local compartmental overload, via correction of malalignment. Clinical experience supports this rationale [72]; however, the long-term effectiveness of HTO for treatment of medial compartment osteoarthritis has not been experimentally confirmed to date. Macroscopical (observations made via arthroscopy) [59, 75, 151] and histological (specimens obtained via punch biopsy) [5] improvements following HTO for unicompartmental osteoarthritis have been reported. However, Koshino et al. [79] showed that no true articular cartilage regeneration occurred, but mere regeneration with fibrocartilaginous tissue. Some authors reported improved outcomes after HTO for medial compartment osteoarthritis of the knee if the malalignment was over-corrected [75, 111, 112, 121, 136]. Birmingham et al. [17] reported on an observational cohort study showing clinically important changes in dynamic knee joint loading and patient-reported measures of pain, function, and quality of life after 2 years after HTO for medial compartment osteoarthritis. Shallberger et al. [120] reported a retrospective study showing slight progression of radiological osteoarthritis an average of 16.5 years following HTO for medial compartment osteoarthritis. Parker et al. reported on 
a small case series of 10 patients demonstrating improved T1Gd relaxation times with delayed gadolinium-enhanced magnetic resonance imaging of cartilage (dGEMRIC) [155] at the medial compartment, which is reflective of glycosaminoglycan content, without significant differences in the lateral compartment, suggesting a potential for articular cartilage recovery secondary to an improved biomechanical environment [115].

In conclusion, malalignment seems to be associated with increased occurrence of and faster progression of radiographic osteoarthritic changes. The evidence regarding high tibial osteotomy (HTO) preventing such changes by restoring a more favorable biomechanical environment is inconclusive, but promising results have been reported. Further studies are needed to increase our understanding of and justify this practice.

\section{Loss of meniscal tissue}

Any substantial loss of meniscal tissue from injury or iatrogenic meniscectomy permanently alters the biomechanical and biological environment of the knee joint [82]. Subtotal or total meniscectomy increases the risk of secondary osteoarthritic changes by a factor 14 when compared to matched controls $[98,118]$, eventually resulting in radiographic changes in $30-70 \%$ of patients $[6,31,119]$. The role of concomitant cartilage damage related to the trauma that resulted in meniscal injury in the first place, or of iatrogenic damage related to the meniscectomy procedures, has not been determined, but is likely to play a role as well [142]. Worse outcomes have been reported in younger patients, and especially those with associated articular co-morbidities such as chondral damage, ligamentous instability, and malalignment [29, 94]. Even though surgeons are cognizant of the deleterious consequences of meniscal resection, meniscal preservation is not possible in many cases. In some patients, meniscal allograft transplantation can normalize the biomechanics, providing excellent pain relief and improved function [144]. Several studies have demonstrated potential chondroprotective effects of the meniscal transplant, with slowing, but not complete cessation of degeneration [132, 144]. It has to be noted, however, that a slight mismatch or malposition of the meniscal transplant may lead to peak loading and cartilage degeneration [142]. This section will review the biomechanical, pre-clinical and clinical data on the effects of meniscectomy and meniscal transplantation.

\section{Meniscectomy}

Initially described as vestigial, non-functional tissue, the menisci have since been found to play a vital role in load transmission in the knee. They transmit $50 \%$ and $70 \%$ of the medial and lateral compartment load, respectively, with the knee in extension [122]. This increases to almost $85 \%$ when the knee is flexed to $90^{\circ}$ [3]. The menisci also serve as an important secondary restraint to antero-posterior joint translation in unstable knees, that is, knees with deficient anterior cruciate ligament [83, 84]. Biomechanical studies have demonstrated significant alteration in load transmission with meniscal deficiency or mismatch [142]. Removal of the central $1 / 3$ of the meniscus results in a $10 \%$ decrease of contact area and $65 \%$ increase in peak local contact stresses, while total meniscectomy leads to a $75 \%$ decrease in contact area and $235 \%$ increase in peak local contact stress $[14,113]$. While frank loss of tissue has logical consequences, even a radial tear with otherwise intact tissue reduces or negates meniscal function: a radial tear to within $3 \mathrm{~mm}$ of the capsule has the same biomechanical effect as removal of the entire central meniscus up to a 3-mm peripheral remnant [74]. Based on this in vitro study, the meniscus remnant is seen as functional if more than $5 \mathrm{~mm}$ wide, and as deficient if less than $3 \mathrm{~mm}$ remain undisturbed along the circumferential hoop fibers. Animal experiments have elaborated on these biomechanical theories, demonstrating degenerative changes proportional to the amount of meniscus removed [39].

Biomechanical and animal models of meniscal repair demonstrated near-normal load transmission [14, 109], providing a rationale for meniscal repair when possible. The same study, however, pointed out the challenges posed by radial tears, which even after successful healing demonstrated decreased contact area [109].

Clinical data reflect the biomechanical changes observed experimentally. Radiographic changes in the knee joint after meniscectomy were noticed as early as 1939; however, Fairbank was the first to describe in 1948 a consistent pattern of ridge formation, femoral flattening and joint space narrowing in 107 patients that had undergone open, most likely complete meniscectomy [54]. Jackson in 1968 reviewed 577 meniscectomized knees, demonstrating increasing numbers of patients with degenerative changes and osteoarthritic symptoms with longer follow-up, reaching 67 and 33\%, respectively, at 30 years follow-up [73]. These findings were confirmed subsequently by multiple authors, supporting Fairbank's theory that meniscectomy predisposes the knee to osteoarthritis, especially when concomitant injuries or abnormalities are present, such as instability or malalignment [29, 94, 98, 117-119]. Relatively few experimental studies on this subject have been performed in vivo besides Voloshin et al. [148] who were able to demonstrate a $20 \%$ reduction in the shock absorption capacity of the knee after meniscectomy. 


\section{Meniscal transplantation}

Biomechanical studies have demonstrated improved contact area and peak stresses with meniscal transplantation, ranging from near normal to normal [7, 113, 145]. Furthermore, due to its function as a secondary stabilizer, meniscal transplantation can reduce tibial translation and strain on the ACL to near-normal [128]. Fixation technique [35] and positioning [78, 149], as well as sizing of the meniscal transplant, appear to have important impact on the effectiveness and biomechanical result. Experimental studies of meniscal transplantation in animals have demonstrated a chondroprotective effect. Even though degenerative changes were not completely avoided, they were reduced in comparison to meniscectomized controls [1, 9, 40, 132].

Clinical information is limited to date. Chondroprotective effects of meniscal transplantation were reported with a lower incidence of osteoarthritis seen in transplanted patients than expected from other natural history studies. Verdonk et al. [144] demonstrated no progression of chondral damage in $40 \%$ of patients, and progression by only 1 grade in an additional 35\% in an average 12-year follow-up study. Overall, patients without malalignment, or with correction through osteotomy, fared better [144]. The optimal fixation techniques and implant positioning remain open issues.

In conclusion, the changes in biomechanical and biological environment of the knee joint following loss of meniscal tissue, either traumatic or following meniscectomy, and the deleterious consequences of those changes on the articular cartilage are well known. There seems to be a rationale for meniscus repair to restore the optimal biomechanical environment whenever possible, however clinical evidence is limited. The same is true regarding the use of meniscal transplantation.

\section{Cartilage defects}

Cartilage lesions are best divided according to their depth into partial-thickness and full-thickens defects. A somewhat distinct category are osteochondral lesions. According to recent studies, partial and full-thickness lesions can progress and even regress from one into another [37, 105]. Partial-thickness lesions are considered less symptomatic, and there is little evidence for their progression onto osteoarthritis [23, 49, 99]. Full-thickness chondral and osteochondral lesions frequently cause symptoms, and they are generally believed to predispose to premature osteoarthritis $[20,23,68,69]$. The cause of the pain in these patients is probably multifactorial and derived mainly from the subchondral bone and peri-articular tissues, although a local rise in intraosseous pressure may play an important role as well [93, 141]. Early focal lesions seen in aging exhibit molecular changes in the extracellular matrix similar to those observed in osteoarthritis [129]. Moreover, the cartilage from the edge of debrided articular defects was inferior to that from a standard donor site when used for autologous chondrocyte cultivation [95]. Focal chondral and osteochondral lesions are common, and they were encountered in about $20 \%$ of knee arthroscopies [41, 70], but also in about $40 \%$ of knee MRI's in healthy subjects without a family history of knee osteoarthritis [50]. Not all of these lesions were related to trauma, and a significant proportion of them were asymptomatic. The scientific evidence on which lesions and under what circumstances in the knee would progress to osteoarthritis is limited. An in vitro study on human cadaveric material determined the influence of osteochondral defect size on defect rim stress concentration, peak rim stress, and load redistribution to adjacent cartilage over the weight-bearing area of the medial and lateral femoral condyles [66]. Rim stress concentration was demonstrated for osteochondral defects $10 \mathrm{~mm}$ and greater in size. The structural changes in the subchondral endplate might be a precursor for lesion's degenerative progression. As defect size increases, more surface area of exposed subchondral bone is contacted by the opposing articular surface, causing endplate stiffening and microcracks. An in vitro study on bovine condyles established that a critical defect area for the subchondral endplate contact was over $1.61 \mathrm{~cm}^{2}$ for lateral condyle and $1.99 \mathrm{~cm}^{2}$ for medial condyle $[57,66]$. Critical defect size is defined as the defect size above which no spontaneous healing occurs. Although the term does not take into account the most important factor of lesion healing response, depth, it is still widely used. The reported critical size defects in animals (given in volumes to allow rough inter-species comparison) range from $18 \mathrm{~mm}^{3}$ in dogs to $142 \mathrm{~mm}^{3}$ in horses [36]. Various animal models have helped us to understand the biology of cartilage repair. However, due to the anatomical and biomechanical differences, the animal models cannot give evidence on the natural history of cartilage defects in humans $[10,125]$.

Classical long-term osteochondritis dissecans studies have demonstrated knee joint dysfunction and high prevalence of osteoarthritic change after fragment removal [68, 85]. On the contrary, the presence of solitary traumatic lesions did not cause a significant clinical deterioration, nor did their presence significantly influence mid-term followup outcome after anterior cruciate ligament reconstruction [71, 154]. Widuchowsky et al. [153] reported no differences in clinical assessment or radiographic osteoarthritic changes between knees with untreated focal cartilage lesions compared to the health controlateral knee. All the studies above bear the limitation of a small defect size from 1.5 to $4.0 \mathrm{~cm}^{2}[48,116]$. On the other hand, patients with 
arthroscopically diagnosed deep cartilage injuries may show improvement in knee function over time, but the function remained substantially inferior to normal [92]. In addition, non-invasive population MRI studies have demonstrated a significant increase of tibiofemoral cartilage loss over 2 years when solitary lesions were present [50]. All these clinical studies focused on solitary lesions within the healthy normal cartilage. However, in the setting of osteoarthritis, Davis-Tuck et al. en Ciccutini et al. clearly showed progressive enlargement over time on MRI $[37,46]$.

The most pertinent unanswered issue is if our cartilage defect repair strategies stop or slow down the development or progression of osteoarthritic changes at all. At present, a well-documented prospective follow-up over 10 years for the treatment of cartilage defects is available only on the classical autologous chondrocyte implantation (ACI) technique. The repair tissue did not develop the unique mechanical properties of native hyaline cartilage, leaving the rim of the defect exposed to increased stresses. Moreover, the increased synovial markers, which were shown to persist in spite of successful ACI, are indicative of continuing cartilage degeneration [101, 116, 143]. Other treatment options include microfracturing [100], polymerbased autologous chondrocyte grafts [80] and resurfacing the defect with a contoured articular prosthesis [16]. Clinical data with sufficient long-term follow-up are for these modalities not yet available.

In conclusion, cartilage defects, depending on size and location, may give rise to increased stresses at the rim of the defect, thereby locally overloading the cartilage and predisposing to osteoarthritic changes. To date, our understanding of the natural history of cartilage defects and the evidence regarding the optimal treatment strategy remain incompletely understood. Restoring the biomechanical environment to near normal seems of paramount importance,

\section{Joint instability or laxity}

Joint laxity and instability have long been considered to be a strong contributor to the development of post-traumatic osteoarthritis [58, 90, 91, 150]. Nonetheless, the definition of instability remains nebulous. Burstein and Wright defined stability as "the ability of a joint to maintain an appropriate functional position throughout its range of motion" [30]. A joint is then stable if, when moving through a normal range of motion, it can carry the required functional loads without pain, while produce joint contact forces of normal intensity on its articular cartilage surfaces [30]. Joint laxity and instability shift the centrally located primary load bearing area to a more peripheral location, resulting in overloading of part of the articular cartilage.
There is a change in both static and dynamic loading, with increased stresses through the articular cartilage [138]. Also, as stated earlier, chondrocytes are particularly sensitive to loading rate [26].

The anterior cruciate ligament (ACL) is the knee ligament most common disrupted [58]. Isolated ACL lesions are uncommon; frequently there is associated injury to other ligamentous structures, the menisci, the articular cartilage or the subchondral plate. Those probably have a major contribution to, but are also by themselves associated with the early development of osteoarthritis [90]. In particular, associated meniscus injury even further compromises joint stability [110]. As stated earlier, the menisci are important secondary constraints to antero-posterior joint translation in unstable, that is, anterior cruciate ligamentdeficient knees [52, 104, 127].

Experimental data from rabbit and canine models suggest a correlation with degenerative cartilage changes and joint instability, with no threshold being evident $[63,137]$. Also in humans, joint instability has long been empirically recognized as a leading risk factor for the development of osteoarthritis. However, there is insufficient evidence that anterior cruciate ligament reconstruction or meniscus repair halt or prevent the development of osteoarthritis in the long term [90]. Even after adequate ACL reconstruction, 50 to $>80 \%$ of injured knees show radiographic osteoarthritic changes at 9 years or more follow-up [91, 131]. Even though ACL reconstruction may to large extent restore antero-posterior stability about the knee, there is evidence that excessive tibial rotation still persists during activities that are more demanding that walking [130]. Even small persisting instability (micro-instability) may lead to supra-physiological cartilage loading and gradual degeneration [137]. This seems even more so, when ACL reconstruction also allows return to participation in sports, which is usually already associated with high-impact loading by itself [56, 90].

Favorable long-term follow-up outcomes in terms of symptoms, function and radiographic appearance have been reported following non-operative treatment of anterior cruciate ligament injury based on neuromuscular knee rehabilitation [108]. Untreated ACL injuries lead to chronic anterior joint instability; this anterior instability has been shown to be associated with an increasing occurrence of posterior meniscal tears when the instability becomes more chronic [52, 76].

In conclusion, joint instability or laxity seems to play an important role in the development of early osteoarthritis. However, the theoretical advantage of reconstructing joint stability on prevention of the development of osteoarthritis in the long-term has to date not been clearly demonstrated by means of methodologically sound studies with sufficiently long-term follow-up. Those studies are clearly 
needed to improve our understanding of and justify our practice regarding ligamentous injury, ACL rupture in particular, about the knee.

\section{Conclusions}

Malalignment, loss of meniscal tissue, cartilage defects and joint instability all seem to be strongly correlated to osteoarthritis in one way or the other. It is important to realize that there are many other etiologies that can cause osteoarthritis, some of which also via mechanically induced pathophysiological changes to the articular cartilage, subchondral bone and other possibly other joint tissues such as, but not limited to, obesity, high-impact sports or labor and neuromuscular dysfunction. Ongoing research efforts will gradually clarify the response of cartilage to mechanical loading and oxidative stress, be it following trauma or related to joint overloading, thereby hopefully allowing us to intercept earlier in the pathophysiological process of osteoarthritis and decreasing the burden of osteoarthritis on society.

Open Access This article is distributed under the terms of the Creative Commons Attribution Noncommercial License which permits any noncommercial use, distribution, and reproduction in any medium, provided the original author(s) and source are credited.

\section{References}

1. Aagaard H, Jorgensen U, Bojsen-Moller F (1999) Reduced degenerative articular cartilage changes after meniscal allograft transplantation in sheep. Knee Surg Sports Traumatol Arthrosc 7:184-191

2. Adams CS, Horton WE Jr (1998) Chondrocyte apoptosis increases with age in the articular cartilage of adult animals. Anat Rec 250:418-425

3. Ahmed AM, Burke DL (1983) In vitro measurement of static pressure distribution in synovial joints-part I: tibial surface of the knee. J Biomech Eng 105:216-225

4. Aigner T, Rose J, Martin J, Buckwalter J (2004) Aging theories of primary osteoarthritis: from epidemiology to molecular biology. Rejuvenation Res 7:134-145

5. Akizuki S, Yasukawa Y, Takizawa T (1997) Does arthroscopic abrasion arthroplasty promote cartilage regeneration in osteoarthritic knees with eburnation? A prospective study of high tibial osteotomy with abrasion arthroplasty versus high tibial osteotomy alone. Arthroscopy 13:9-17

6. Alford JW, Lewis P, Kang RW, Cole BJ (2005) Rapid progression of chondral disease in the lateral compartment of the knee following meniscectomy. Arthroscopy 21:1505-1509

7. Alhalki MM, Hull ML, Howell SM (2000) Contact mechanics of the medial tibial plateau after implantation of a medial meniscal allograft. A human cadaveric study. Am J Sports Med 28: 370-376

8. Andriacchi TP (1994) Dynamics of knee malalignment. Orthop Clin North Am 25:395-403
9. Arnoczky SP, Warren RF, McDevitt CA (1990) Meniscal replacement using a cryopreserved allograft. An experimental study in the dog. Clin Orthop Relat Res 252:121-128

10. Athanasiou KA, Rosenwasser MP, Buckwalter JA, Malinin TI, Mow VC (1991) Interspecies comparisons of in situ intrinsic mechanical properties of distal femoral cartilage. J Orthop Res 9:330-340

11. Atkinson TS, Haut RC, Altiero NJ (1998) An investigation of biphasic failure criteria for impact-induced fissuring of articular cartilage. J Biomech Eng 120:536-537

12. Atkinson TS, Haut RC, Altiero NJ (1998) Impact-induced fissuring of articular cartilage: an investigation of failure criteria. J Biomech Eng 120:181-187

13. Baliunas AJ, Hurwitz DE, Ryals AB, Karrar A, Case JP, Block JA, Andriacchi TP (2002) Increased knee joint loads during walking are present in subjects with knee osteoarthritis. Osteoarthr Cartil 10:573-579

14. Baratz ME, Fu FH, Mengato R (1986) Meniscal tears: the effect of meniscectomy and of repair on intraarticular contact areas and stress in the human knee. A preliminary report. Am J Sports Med 14:270-275

15. Bayliss MT, Osborne D, Woodhouse S, Davidson C (1999) Sulfation of chondroitin sulfate in human articular cartilage. The effect of age, topographical position, and zone of cartilage on tissue composition. J Biol Chem 274:15892-15900

16. Becher C, Huber R, Thermann H, Paessler HH, Skrbensky G (2008) Effects of a contoured articular prosthetic device on tibiofemoral peak contact pressure: a biomechanical study. Knee Surg Sports Traumatol Arthrosc 16:56-63

17. Birmingham TB, Giffin JR, Chesworth BM, Bryant DM, Litchfield RB, Willits K, Jenkyn TR, Fowler PJ (2009) Medial opening wedge high tibial osteotomy: a prospective cohort study of gait, radiographic, and patient-reported outcomes. Arthritis Rheum 61:648-657

18. Block JA, Shakoor N (2010) Lower limb osteoarthritis: biomechanical alterations and implications for therapy. Curr Opin Rheumatol 22:544-550

19. Brandt KD (2003) Response of joint structures to inactivity and to reloading after immobilization. Arthritis Rheum 49: 267-271

20. Brittberg M, Lindahl A, Nilsson A, Ohlsson C, Isaksson O, Peterson L (1994) Treatment of deep cartilage defects in the knee with autologous chondrocyte transplantation. N Engl J Med 331:889-895

21. Brouwer GM, van Tol AW, Bergink AP, Belo JN, Bernsen RM, Reijman M, Pols HA, Bierma-Zeinstra SM (2007) Association between valgus and varus alignment and the development and progression of radiographic osteoarthritis of the knee. Arthritis Rheum 56:1204-1211

22. Buckwalter JA (1995) Osteoarthritis and articular cartilage use, disuse, and abuse: experimental studies. J Rheumatol Suppl 43: $13-15$

23. Buckwalter JA (2002) Articular cartilage injuries. Clin Orthop Relat Res 402:21-37

24. Buckwalter JA (2003) Sports, joint injury, and posttraumatic osteoarthritis. J Orthop Sports Phys Ther 33:578-588

25. Buckwalter JA, Mankin HJ, Grodzinsky AJ (2005) Articular cartilage and osteoarthritis. Instr Course Lect 54:465-480

26. Buckwalter JA, Martin JA, Brown TD (2006) Perspectives on chondrocyte mechanobiology and osteoarthritis. Biorheology 43:603-609

27. Buckwalter JA, Roughley PJ, Rosenberg LC (1994) Age-related changes in cartilage proteoglycans: quantitative electron microscopic studies. Microsc Res Tech 28:398-408 
28. Bullough PG (2007) Joints. In: Mills SE (ed) Histology for pathologists, 3rd edn. Lippincott Williams \& Wilkins, Philapelphia, pp 97-121

29. Burks RT, Metcalf MH, Metcalf RW (1997) Fifteen-year follow-up of arthroscopic partial meniscectomy. Arthroscopy 13: 673-679

30. Burstein AH, Wright TM (1994) Joint stability. In: Burstein AH, Wright TM (eds) Fundamentals of orthopedic biomechanics, 1st edn. Williams \& Wilkins, Baltimore, pp 63-93

31. Cameron JC, Saha S (1997) Meniscal allograft transplantation for unicompartmental arthritis of the knee. Clin Orthop Relat Res 337:164-171

32. Campisi J (2005) Senescent cells, tumor suppression, and organismal aging: good citizens, bad neighbors. Cell 120:513-522

33. Campisi J, di d'Adda FF (2007) Cellular senescence: when bad things happen to good cells. Natl Rev Mol Cell Biol 8:729-740

34. Cerejo R, Dunlop DD, Cahue S, Channin D, Song J, Sharma L (2002) The influence of alignment on risk of knee osteoarthritis progression according to baseline stage of disease. Arthritis Rheum 46:2632-2636

35. Chen MI, Branch TP, Hutton WC (1996) Is it important to secure the horns during lateral meniscal transplantation? A cadaveric study. Arthroscopy 12:174-181

36. Chu CR, Szczodry M, Bruno S (2010) Animal models for cartilage regeneration and repair. Tissue Eng Part B Rev 16: $105-115$

37. Cicuttini F, Ding C, Wluka A, Davis S, Ebeling PR, Jones G (2005) Association of cartilage defects with loss of knee cartilage in healthy, middle-age adults: a prospective study. Arthritis Rheum 52:2033-2039

38. Cicuttini F, Wluka A, Hankin J, Wang Y (2004) Longitudinal study of the relationship between knee angle and tibiofemoral cartilage volume in subjects with knee osteoarthritis. Rheumatology (Oxford) 43:321-324

39. Cox JS, Nye CE, Schaefer WW, Woodstein IJ (1975) The degenerative effects of partial and total resection of the medial meniscus in dogs' knees. Clin Orthop Relat Res 109:178-183

40. Cummins JF, Mansour JN, Howe Z, Allan DG (1997) Meniscal transplantation and degenerative articular change: an experimental study in the rabbit. Arthroscopy 13:485-491

41. Curl WW, Krome J, Gordon ES, Rushing J, Smith BP, Poehling GG (1997) Cartilage injuries: a review of 31, 516 knee arthroscopies. Arthroscopy 13:456-460

42. D'Lima DD, Hashimoto S, Chen PC, Colwell CW Jr, Lotz MK (2001) Human chondrocyte apoptosis in response to mechanical injury. Osteoarthr Cartil 9:712-719

43. D'Lima DD, Hashimoto S, Chen PC, Lotz MK, Colwell CW, Jr (2001) Prevention of chondrocyte apoptosis. J Bone Joint Surg Am 83-A(Suppl 2):25-26

44. Dai SM, Shan ZZ, Nakamura H, Masuko-Hongo K, Kato T, Nishioka K, Yudoh K (2006) Catabolic stress induces features of chondrocyte senescence through overexpression of caveolin 1: possible involvement of caveolin 1-induced down-regulation of articular chondrocytes in the pathogenesis of osteoarthritis. Arthritis Rheum 54:818-831

45. Davies CM, Guilak F, Weinberg JB, Fermor B (2008) Reactive nitrogen and oxygen species in interleukin-1-mediated DNA damage associated with osteoarthritis. Osteoarthr Cartil 16: 624-630

46. Davies-Tuck ML, Wluka AE, Wang Y, Teichtahl AJ, Jones G, Ding C, Cicuttini FM (2008) The natural history of cartilage defects in people with knee osteoarthritis. Osteoarthr Cartil 16: 337-342

47. DeGroot J, Verzijl N, Bank RA, Lafeber FP, Bijlsma JW, TeKoppele JM (1999) Age-related decrease in proteoglycan synthesis of human articular chondrocytes: the role of nonenzymatic glycation. Arthritis Rheum 42:1003-1009

48. Dell'accio F, Vincent TL (2010) Joint surface defects: clinical course and cellular response in spontaneous and experimental lesions. Eur Cell Mater 20:210-217

49. Ding C, Cicuttini F, Scott F, Boon C, Jones G (2005) Association of prevalent and incident knee cartilage defects with loss of tibial and patellar cartilage: a longitudinal study. Arthritis Rheum 52:3918-3927

50. Ding C, Garnero P, Cicuttini F, Scott F, Cooley H, Jones G (2005) Knee cartilage defects: association with early radiographic osteoarthritis, decreased cartilage volume, increased joint surface area and type II collagen breakdown. Osteoarthr Cartil 13:198-205

51. Dudhia J, Davidson CM, Wells TM, Vynios DH, Hardingham TE, Bayliss MT (1996) Age-related changes in the content of the C-terminal region of aggrecan in human articular cartilage. Biochem J 313(Pt 3):933-940

52. Durselen L, Vogele S, Seitz AM, Ignatius A, Friederich NF, Bauer G, Majewski M (2011) Anterior knee laxity increases gapping of posterior horn medial meniscal tears. Am J Sports Med 39:1749-1755

53. Ewers BJ, Dvoracek-Driksna D, Orth MW, Haut RC (2001) The extent of matrix damage and chondrocyte death in mechanically traumatized articular cartilage explants depends on rate of loading. J Orthop Res 19:779-784

54. Fairbank TJ (1948) Knee joint changes after meniscectomy. J Bone Joint Surg Br 30B:664-670

55. Felson DT, Gale DR, Elon GM, Niu J, Hunter DJ, Goggins J, Lavalley MP (2005) Osteophytes and progression of knee osteoarthritis. Rheumatology (Oxford) 44:100-104

56. Fithian DC, Paxton LW, Goltz DH (2002) Fate of the anterior cruciate ligament-injured knee. Orthop Clin North Am 33:621-636

57. Flanigan DC, Harris JD, Brockmeier PM, Siston RA (2010) The effects of lesion size and location on subchondral bone contact in experimental knee articular cartilage defects in a bovine model. Arthroscopy 26:1655-1661

58. Frobell RB, Lohmander LS, Roos HP (2007) Acute rotational trauma to the knee: poor agreement between clinical assessment and magnetic resonance imaging findings. Scand J Med Sci Sports 17:109-114

59. Fujisawa Y, Masuhara K, Shiomi S (1979) The effect of high tibial osteotomy on osteoarthritis of the knee. An arthroscopic study of 54 knee joints. Orthop Clin North Am 10:585-608

60. Goldring MB, Goldring SR (2007) Osteoarthritis. J Cell Physiol 213:626-634

61. Gomoll AH, Madry H, Knutsen G, van Dijk N, Seil R, Brittberg M, Kon E (2010) The subchondral bone in articular cartilage repair: current problems in the surgical management. Knee Surg Sports Traumatol Arthrosc 18:434-447

62. Griffin TM, Guilak F (2005) The role of mechanical loading in the onset and progression of osteoarthritis. Exerc Sport Sci Rev 33:195-200

63. Griffith CJ, Wijdicks CA, Goerke U, Michaeli S, Ellermann J, Laprade RF (2011) Outcomes of untreated posterolateral knee injuries: an in vivo canine model. Knee Surg Sports Traumatol Arthrosc 19:1192-1197

64. Grodzinsky AJ, Levenston ME, Jin M, Frank EH (2000) Cartilage tissue remodeling in response to mechanical forces. Annu Rev Biomed Eng 2:691-713

65. Grushko G, Schneiderman R, Maroudas A (1989) Some biochemical and biophysical parameters for the study of the pathogenesis of osteoarthritis: a comparison between the processes of ageing and degeneration in human hip cartilage. Connect Tissue Res 19:149-176 
66. Guettler JH, Demetropoulos CK, Yang KH, Jurist KA (2004) Osteochondral defects in the human knee: influence of defect size on cartilage rim stress and load redistribution to surrounding cartilage. Am J Sports Med 32:1451-1458

67. Hayflick L (1984) Intracellular determinants of cell aging. Mech Ageing Dev 28:177-185

68. Hefti F, Beguiristain J, Krauspe R, Moller-Madsen B, Riccio V, Tschauner C, Wetzel R, Zeller R (1999) Osteochondritis dissecans: a multicenter study of the European Pediatric Orthopedic Society. J Pediatr Orthop B 8:231-245

69. Heir S, Nerhus TK, Rotterud JH, Loken S, Ekeland A, Engebretsen L, Aroen A (2010) Focal cartilage defects in the knee impair quality of life as much as severe osteoarthritis: a comparison of knee injury and osteoarthritis outcome score in 4 patient categories scheduled for knee surgery. Am J Sports Med 38:231-237

70. Hjelle K, Solheim E, Strand T, Muri R, Brittberg M (2002) Articular cartilage defects in 1,000 knee arthroscopies. Arthroscopy 18:730-734

71. Hjermundrud V, Bjune TK, Risberg MA, Engebretsen L, Aroen A (2010) Full-thickness cartilage lesion do not affect knee function in patients with ACL injury. Knee Surg Sports Traumatol Arthrosc 18:298-303

72. Hunter DJ, Zhang Y, Niu J, Tu X, Amin S, Goggins J, Lavalley M, Guermazi A, Gale D, Felson DT (2005) Structural factors associated with malalignment in knee osteoarthritis: the Boston osteoarthritis knee study. J Rheumatol 32:2192-2199

73. Jackson JP (1968) Degenerative changes in the knee after meniscectomy. Br Med J 2:525-527

74. Jones RS, Keene GC, Learmonth DJ, Bickerstaff D, Nawana NS, Costi JJ, Pearcy MJ (1996) Direct measurement of hoop strains in the intact and torn human medial meniscus. Clin Biomech (Bristol, Avon) 11:295-300

75. Kanamiya T, Naito M, Hara M, Yoshimura I (2002) The influences of biomechanical factors on cartilage regeneration after high tibial osteotomy for knees with medial compartment osteoarthritis: clinical and arthroscopic observations. Arthroscopy $18: 725-729$

76. Keene GC, Bickerstaff D, Rae PJ, Paterson RS (1993) The natural history of meniscal tears in anterior cruciate ligament insufficiency. Am J Sports Med 21:672-679

77. Kirkwood TB (1997) What is the relationship between osteoarthritis and ageing? Baillieres Clin Rheumatol 11:683-694

78. Kohn D, Moreno B (1995) Meniscus insertion anatomy as a basis for meniscus replacement: a morphological cadaveric study. Arthroscopy 11:96-103

79. Koshino T, Wada S, Ara Y, Saito T (2003) Regeneration of degenerated articular cartilage after high tibial valgus osteotomy for medial compartmental osteoarthritis of the knee. Knee 10: 229-236

80. Kreuz PC, Muller S, Ossendorf C, Kaps C, Erggelet C (2009) Treatment of focal degenerative cartilage defects with polymerbased autologous chondrocyte grafts: four-year clinical results. Arthritis Res Ther 11:R33

81. Kurz B, Lemke A, Kehn M, Domm C, Patwari P, Frank EH, Grodzinsky AJ, Schunke M (2004) Influence of tissue maturation and antioxidants on the apoptotic response of articular cartilage after injurious compression. Arthritis Rheum 50: 123-130

82. Lee SJ, Aadalen KJ, Malaviya P, Lorenz EP, Hayden JK, Farr J, Kang RW, Cole BJ (2006) Tibiofemoral contact mechanics after serial medial meniscectomies in the human cadaveric knee. Am J Sports Med 34:1334-1344

83. Levy IM, Torzilli PA, Gould JD, Warren RF (1989) The effect of lateral meniscectomy on motion of the knee. J Bone Joint Surg Am 71:401-406
84. Levy IM, Torzilli PA, Warren RF (1982) The effect of medial meniscectomy on anterior-posterior motion of the knee. J Bone Joint Surg Am 64:883-888

85. Linden B (1977) Osteochondritis dissecans of the femoral condyles: a long-term follow-up study. J Bone Joint Surg Am 59:769-776

86. Loeser RF Jr (2000) Aging and the etiopathogenesis and treatment of osteoarthritis. Rheum Dis Clin North Am 26:547-567

87. Loeser RF (2009) Aging and osteoarthritis: the role of chondrocyte senescence and aging changes in the cartilage matrix. Osteoarthr Cartil 17:971-979

88. Loeser RF (2010) Age-related changes in the musculoskeletal system and the development of osteoarthritis. Clin Geriatr Med 26:371-386

89. Loeser RF, Carlson CS, Del CM, Cole A (2002) Detection of nitrotyrosine in aging and osteoarthritic cartilage: Correlation of oxidative damage with the presence of interleukin-1beta and with chondrocyte resistance to insulin-like growth factor 1 . Arthritis Rheum 46:2349-2357

90. Lohmander LS, Englund PM, Dahl LL, Roos EM (2007) The long-term consequence of anterior cruciate ligament and meniscus injuries: osteoarthritis. Am J Sports Med 35: $1756-1769$

91. Lohmander LS, Ostenberg A, Englund M, Roos H (2004) High prevalence of knee osteoarthritis, pain, and functional limitations in female soccer players twelve years after anterior cruciate ligament injury. Arthritis Rheum 50:3145-3152

92. Loken S, Heir S, Holme I, Engebretsen L, Aroen A (2010) 6-year follow-up of 84 patients with cartilage defects in the knee. Knee scores improved but recovery was incomplete. Acta Orthop 81:611-618

93. Madry H, van Dijk CN, Mueller-Gerbl M (2010) The basic science of the subchondral bone. Knee Surg Sports Traumatol Arthrosc 18:419-433

94. Maletius W, Messner K (1996) The effect of partial meniscectomy on the long-term prognosis of knees with localized, severe chondral damage. A twelve- to fifteen-year followup. Am J Sports Med 24:258-262

95. Malicev E, Barlic A, Kregar-Velikonja N, Strazar K, Drobnic M (2011) Cartilage from the edge of a debrided articular defect is inferior to that from a standard donor site when used for autologous chondrocyte cultivation. J Bone Joint Surg $\mathrm{Br}$ 93:421-426

96. Marsh JL, Buckwalter J, Gelberman R, Dirschl D, Olson S, Brown T, Llinias A (2002) Articular fractures: does an anatomic reduction really change the result? J Bone Joint Surg Am 84-A: $1259-1271$

97. Martin JA, Buckwalter JA (2002) Aging, articular cartilage chondrocyte senescence and osteoarthritis. Biogerontology 3: 257-264

98. McNicholas MJ, Rowley DI, McGurty D, Adalberth T, Abdon P, Lindstrand A, Lohmander LS (2000) Total meniscectomy in adolescence. A thirty-year follow-up. J Bone Joint Surg Br 82: 217-221

99. Messner K, Maletius W (1996) The long-term prognosis for severe damage to weight-bearing cartilage in the knee: a 14-year clinical and radiographic follow-up in 28 young athletes. Acta Orthop Scand 67:165-168

100. Miller BS, Steadman JR, Briggs KK, Rodrigo JJ, Rodkey WG (2004) Patient satisfaction and outcome after microfracture of the degenerative knee. J Knee Surg 17:13-17

101. Minas T, Gomoll AH, Solhpour S, Rosenberger R, Probst C, Bryant $T$ (2010) Autologous chondrocyte implantation for joint preservation in patients with early osteoarthritis. Clin Orthop Relat Res 468:147-157

102. Miyazaki T, Wada M, Kawahara H, Sato M, Baba H, Shimada S (2002) Dynamic load at baseline can predict radiographic 
disease progression in medial compartment knee osteoarthritis. Ann Rheum Dis 61:617-622

103. Moyer RF, Birmingham TB, Chesworth BM, Kean CO, Giffin JR (2010) Alignment, body mass and their interaction on dynamic knee joint load in patients with knee osteoarthritis. Osteoarthr Cartil 18:888-893

104. Musahl V, Citak M, O’Loughlin PF, Choi D, Bedi A, Pearle AD (2010) The effect of medial versus lateral meniscectomy on the stability of the anterior cruciate ligament-deficient knee. Am J Sports Med 38:1591-1597

105. Nakamura N, Horibe S, Toritsuka Y, Mitsuoka T, Natsu-ume T, Yoneda K, Hamada M, Tanaka Y, Boorman RS, Yoshikawa H, Shino K (2008) The location-specific healing response of damaged articular cartilage after ACL reconstruction: short-term follow-up. Knee Surg Sports Traumatol Arthrosc 16:843-848

106. Neogi T, Felson D, Niu J, Lynch J, Nevitt M, Guermazi A, Roemer F, Lewis CE, Wallace B, Zhang Y (2009) Cartilage loss occurs in the same subregions as subchondral bone attrition: a within-knee subregion-matched approach from the Multicenter Osteoarthritis Study. Arthritis Rheum 61:1539-1544

107. Neogi T, Nevitt M, Niu J, Sharma L, Roemer F, Guermazi A, Lewis CE, Torner J, Javaid K, Felson D (2010) Subchondral bone attrition may be a reflection of compartment-specific mechanical load: the MOST Study. Ann Rheum Dis 69:841-844

108. Neuman P, Kostogiannis I, Friden T, Roos H, Dahlberg LE, Englund M (2010) Knee laxity after complete anterior cruciate ligament tear: a prospective study over 15 years. Scand J Med Sci Sports (epub ahead of print)

109. Newman AP, Anderson DR, Daniels AU, Dales MC (1989) Mechanics of the healed meniscus in a canine model. Am J Sports Med 17:164-175

110. Noyes FR, Bassett RW, Grood ES, Butler DL (1980) Arthroscopy in acute traumatic hemarthrosis of the knee. Incidence of anterior cruciate tears and other injuries. J Bone Joint Surg Am 62:687-695 (757)

111. Odenbring S, Egund N, Hagstedt B, Larsson J, Lindstrand A, Toksvig-Larsen S (1991) Ten-year results of tibial osteotomy for medial gonarthrosis. The influence of overcorrection. Arch Orthop Trauma Surg 110:103-108

112. Odenbring S, Egund N, Lindstrand A, Lohmander LS, Willen H (1992) Cartilage regeneration after proximal tibial osteotomy for medial gonarthrosis. An arthroscopic, roentgenographic, and histologic study. Clin Orthop Relat Res 277:210-216

113. Paletta GA Jr, Manning T, Snell E, Parker R, Bergfeld J (1997) The effect of allograft meniscal replacement on intraarticular contact area and pressures in the human knee. A biomechanical study. Am J Sports Med 25:692-698

114. Paley D, Pfeil J (2000) Principles of deformity correction around the knee. Orthopade 29:18-38

115. Parker DA, Beatty KT, Giuffre B, Scholes CJ, Coolican MR (2011) Articular cartilage changes in patients with osteoarthritis after osteotomy. Am J Sports Med 39:1039-1045

116. Peterson L, Vasiliadis HS, Brittberg M, Lindahl A (2010) Autologous chondrocyte implantation: a long-term follow-up. Am J Sports Med 38:1117-1124

117. Rangger C, Klestil T, Gloetzer W, Kemmler G, Benedetto KP (1995) Osteoarthritis after arthroscopic partial meniscectomy. Am J Sports Med 23:240-244

118. Roos EM, Ostenberg A, Roos H, Ekdahl C, Lohmander LS (2001) Long-term outcome of meniscectomy: symptoms, function, and performance tests in patients with or without radiographic osteoarthritis compared to matched controls. Osteoarthr Cartil 9:316-324

119. Roos H, Lauren M, Adalberth T, Roos EM, Jonsson K, Lohmander LS (1998) Knee osteoarthritis after meniscectomy: prevalence of radiographic changes after twenty-one years, compared with matched controls. Arthritis Rheum 41:687-693

120. Schallberger A, Jacobi M, Wahl P, Maestretti G, Jakob RP (2011) High tibial valgus osteotomy in unicompartmental medial osteoarthritis of the knee: a retrospective follow-up study over 13-21 years. Knee Surg Sports Traumatol Arthrosc 19: $122-127$

121. Schultz W, Gobel D (1999) Articular cartilage regeneration of the knee joint after proximal tibial valgus osteotomy: a prospective study of different intra- and extra-articular operative techniques. Knee Surg Sports Traumatol Arthrosc 7:29-36

122. Seedhom BB, Hargreaves DJ (1979) Transmission of the load in the knee joint with special reference to the role of the menisci part II: experimental results, discussion and conclusion. Eng Med 8:220-228

123. Shane AA, Loeser RF (2010) Why is osteoarthritis an agerelated disease? Best Pract Res Clin Rheumatol 24:15-26

124. Sharma L, Song J, Felson DT, Cahue S, Shamiyeh E, Dunlop DD (2001) The role of knee alignment in disease progression and functional decline in knee osteoarthritis. JAMA 286:188-195

125. Shelbourne KD, Jari S, Gray T (2003) Outcome of untreated traumatic articular cartilage defects of the knee: a natural history study. J Bone Joint Surg Am 85-A(Suppl 2):8-16

126. Shelburne KB, Torry MR, Pandy MG (2006) Contributions of muscles, ligaments, and the ground-reaction force to tibiofemoral joint loading during normal gait. J Orthop Res 24: 1983-1990

127. Shoemaker SC, Markolf KL (1986) The role of the meniscus in the anterior-posterior stability of the loaded anterior cruciatedeficient knee. Effects of partial versus total excision. J Bone Joint Surg Am 68:71-79

128. Spang JT, Dang AB, Mazzocca A, Rincon L, Obopilwe E, Beynnon B, Arciero RA (2010) The effect of medial meniscectomy and meniscal allograft transplantation on knee and anterior cruciate ligament biomechanics. Arthroscopy 26: 192-201

129. Squires GR, Okouneff S, Ionescu M, Poole AR (2003) The pathobiology of focal lesion development in aging human articular cartilage and molecular matrix changes characteristic of osteoarthritis. Arthritis Rheum 48:1261-1270

130. Stergiou N, Ristanis S, Moraiti C, Georgoulis AD (2007) Tibial rotation in anterior cruciate ligament (ACL)-deficient and ACLreconstructed knees: a theoretical proposition for the development of osteoarthritis. Sports Med 37:601-613

131. Sutherland AG, Cooper K, Alexander LA, Nicol M, Smith FW, Scotland TR (2010) The long-term functional and radiological outcome after open reconstruction of the anterior cruciate ligament. J Bone Joint Surg Br 92:1096-1099

132. Szomor ZL, Martin TE, Bonar F, Murrell GA (2000) The protective effects of meniscal transplantation on cartilage. An experimental study in sheep. J Bone Joint Surg Am 82:80-88

133. Tanamas S, Hanna FS, Cicuttini FM, Wluka AE, Berry P, Urquhart DM (2009) Does knee malalignment increase the risk of development and progression of knee osteoarthritis? A systematic review. Arthritis Rheum 61:459-467

134. Taylor WR, Heller MO, Bergmann G, Duda GN (2004) Tibiofemoral loading during human gait and stair climbing. J Orthop Res 22:625-632

135. Tetsworth K, Paley D (1994) Malalignment and degenerative arthropathy. Orthop Clin North Am 25:367-377

136. Tjornstrand B, Egund N, Hagstedt B, Lindstrand A (1981) Tibial osteotomy in medial gonarthrosis. The importance of over-correction of varus deformity. Arch Orthop Trauma Surg 99:83-89

137. Tochigi Y, Rudert MJ, McKinley TO, Pedersen DR, Brown TD (2008) Correlation of dynamic cartilage contact stress 
aberrations with severity of instability in ankle incongruity. J Orthop Res 26:1186-1193

138. Tochigi Y, Vaseenon T, Heiner AD, Fredericks DC, Martin JA, Rudert MJ, Hillis SL, Brown TD, McKinley TO (2011) Instability dependency of osteoarthritis development in a rabbit model of graded anterior cruciate ligament transection. J Bone Joint Surg Am 93:640-647

139. Urban JP (2000) Present perspectives on cartilage and chondrocyte mechanobiology. Biorheology 37:185-190

140. van Dijk CN, Lim LS, Poortman A, Strubbe EH, Marti RK (1995) Degenerative joint disease in female ballet dancers. Am J Sports Med 23:295-300

141. van Dijk CN, Reilingh ML, Zengerink M, van Bergen CJ (2010) Osteochondral defects in the ankle: why painful? Knee Surg Sports Traumatol Arthrosc 18:570-580

142. van Dijk CN, Tol JL, Struijs PAA (1997) Complications, rehabilitation and results of arthroscopic meniscectomy and meniscal repair: a review of the literature. J Sports Traumatol rel res 19:43-50

143. Vasara AI, Konttinen YT, Peterson L, Lindahl A, Kiviranta I (2009) Persisting high levels of synovial fluid markers after cartilage repair: a pilot study. Clin Orthop Relat Res 467: 267-272

144. Verdonk PC, Verstraete KL, Almqvist KF, De CK, Veys EM, Verbruggen G, Verdonk R (2006) Meniscal allograft transplantation: long-term clinical results with radiological and magnetic resonance imaging correlations. Knee Surg Sports Traumatol Arthrosc 14:694-706

145. Verma NN, Kolb E, Cole BJ, Berkson MB, Garretson R, Farr J, Fregly B (2008) The effects of medial meniscal transplantation techniques on intra-articular contact pressures. J Knee Surg 21: 20-26

146. Verzijl N, Bank RA, TeKoppele JM, DeGroot J (2003) AGEing and osteoarthritis: a different perspective. Curr Opin Rheumatol 15:616-622

147. Verzijl N, DeGroot J, Ben ZC, Brau-Benjamin O, Maroudas A, Bank RA, Mizrahi J, Schalkwijk CG, Thorpe SR, Baynes JW, Bijlsma JW, Lafeber FP, TeKoppele JM (2002) Crosslinking by advanced glycation end products increases the stiffness of the collagen network in human articular cartilage: a possible mechanism through which age is a risk factor for osteoarthritis. Arthritis Rheum 46:114-123

148. Voloshin AS, Wosk J (1983) Shock absorption of meniscectomized and painful knees: a comparative in vivo study. J Biomed Eng 5:157-161
149. von Lewinski G, Kohn D, Wirth CJ, Lazovic D (2008) The influence of nonanatomical insertion and incongruence of meniscal transplants on the articular cartilage in an ovine model. Am J Sports Med 36:841-850

150. von Porat A, Roos EM, Roos H (2004) High prevalence of osteoarthritis 14 years after an anterior cruciate ligament tear in male soccer players: a study of radiographic and patient relevant outcomes. Ann Rheum Dis 63:269-273

151. Wakabayashi S, Akizuki S, Takizawa T, Yasukawa Y (2002) A comparison of the healing potential of fibrillated cartilage versus eburnated bone in osteoarthritic knees after high tibial osteotomy: an arthroscopic study with 1-year follow-up. Arthroscopy 18:272-278

152. Wells T, Davidson C, Morgelin M, Bird JL, Bayliss MT, Dudhia J (2003) Age-related changes in the composition, the molecular stoichiometry and the stability of proteoglycan aggregates extracted from human articular cartilage. Biochem J 370:69-79

153. Widuchowski W, Widuchowski J, Faltus R, Lukasik P, Kwiatkowski G, Szyluk K, Koczy B (2011) Long-term clinical and radiological assessment of untreated severe cartilage damage in the knee: a natural history study. Scand J Med Sci Sports 21: $106-110$

154. Widuchowski W, Widuchowski J, Koczy B, Szyluk K (2009) Untreated asymptomatic deep cartilage lesions associated with anterior cruciate ligament injury: results at 10- and 15-year follow-up. Am J Sports Med 37:688-692

155. Williams A, Mikulis B, Krishnan N, Gray M, McKenzie C, Burstein D (2007) Suitability of T(1Gd) as the dGEMRIC index at 1.5T and 3.0T. Magn Reson Med 58:830-834

156. Yin W, Park JI, Loeser RF (2009) Oxidative stress inhibits insulin-like growth factor-I induction of chondrocyte proteoglycan synthesis through differential regulation of phosphatidylinositol 3-Kinase-Akt and MEK-ERK MAPK signaling pathways. J Biol Chem 284:31972-31981

157. Yudoh K, Nguyen T, Nakamura H, Hongo-Masuko K, Kato T, Nishioka K (2005) Potential involvement of oxidative stress in cartilage senescence and development of osteoarthritis: oxidative stress induces chondrocyte telomere instability and downregulation of chondrocyte function. Arthritis Res Ther 7: R380-R391 